\title{
Long-Term Biological Response of Injured Rat Carotid Artery Seeded with Smooth Muscle Cells Expressing Retrovirally Introduced Human Genes
}

\author{
Monika M. Clowes, * Carmel M. Lynch, ' A. Dusty Miller, 'Daniel G. Miller, ' William R. A. Osborne, ${ }^{*}$ and Alexander W. Clowes * \\ Departments of * Surgery and ${ }^{\ddagger}$ Pediatrics, University of Washington, Seattle, Washington 98195; and ${ }^{\S}$ Program in Molecular Medicine, \\ Fred Hutchinson Cancer Center, Seattle, Washington 98104
}

\begin{abstract}
Cultured vascular smooth muscle cells (SMCs) containing retrovirally introduced genes are a potential vehicle for gene replacement therapy. Because the cultured SMCs are selected for their ability to proliferate in vitro, it is possible that the SMCs might be permanently altered and lose their capacity to respond to growth-suppressing conditions after being seeded back into blood vessels. To investigate this possibility we measured SMC proliferation and intimal thickening in balloon-injured Fischer 344 rat carotid arteries seeded with SMCs stained with the fluorescent marker 1,1'-dioctadecyl-3,3,3',3'-tetramethylindocarbocyanine perchlorate (DiI) and infected with replicationdefective retrovirus expressing human adenosine deaminase or human placental alkaline phosphatase. The majority of the seeded SMCs remained in the intima while a few of the cells appeared to migrate into the first layer of the media. Intimal SMC proliferation returned to background levels $(<0.1 \%$ thymidine labeling index) by $28 \mathrm{~d}$. At late times ( 1 and $12 \mathrm{mo}$ ) the morphological appearance of the intima was the same for balloon-injured arteries with or without seeded SMC, except that the seeded arteries continued to express human adenosine deaminase or alkaline phosphatase. These results support the conclusion that cultured SMC infected with a replication-defective virus containing human adenosine deaminase or alkaline phosphatase are not phenotypically altered and do not become transformed. After seeding onto the surface of an injured artery, they stop replicating but continue to express the introduced human genes even over the long term. (J. Clin. Invest. 1994. 93:644-651.) Key words: smooth muscle cell • gene therapy $\bullet$ adenosine deaminase $\bullet$ alkaline phosphatase $\bullet$ retroviral vectors
\end{abstract}

\section{Introduction}

When smooth muscle cells (SMCs) ${ }^{1}$ proliferate in response to arterial injury, their ultrastructural appearance changes $(1,2)$. They exhibit decreased numbers of myofilaments and in-

Address correspondence to Dr. Alexander W. Clowes, Department of Surgery, University of Washington, RF-25, Seattle, WA 98195.

Received for publication 10 February 1993 and in revised form 13 September 1993.

1. Abbreviations used in this paper: hADA, human adenosine deaminase; Neo, neomycin phosphotransferase; SMC, smooth muscle cell.

J. Clin. Invest.

(c) The American Society for Clinical Investigation, Inc. 0021-9738/94/02/0644/08 \$2.00

Volume 93, February 1994, 644-651 creased amounts of rough endoplasmic reticulum while they are proliferating, and as the cells resume quiescence, the morphology reverts to normal. These morphological changes are reflected in other phenotypic alterations (3-5). In association with entry into the growth state, SMCs express less smooth muscle myosin, alpha actin, and desmin, and more nonmuscle myosin, beta actin, and vimentin than cells in quiescence. In addition, they express other cytoplasmic genes, including proto-oncogenes generally associated with the transition from quiescence to the growth state (e.g., c- $f o s, \mathrm{c}-m y c$, ornithine decarboxylase, PDGF A chain, c-myb) (6-13).

To some extent, these markers of transition are preserved or are reinduced selectively when cells are put into culture (14). For example, SMCs from newborn rat aorta or from the neointima of injured rat carotid artery express more PDGF B chain mRNA and PDGF-like protein than cells derived from normal adult rat aorta (9). Cells in culture express less alpha actin and more nonmuscle actin than quiescent cells in vivo $(15,16)$. Once in culture, the phenotypic features of activated SMCs do not change even after many passages, and the quiescent phenotype characteristic of SMCs in vivo is difficult to reinduce. Although the growth of these cells can be arrested, the thymidine labeling index never returns to the low levels seen in normal arteries (culture, typically 1-5\%; normal artery, $\leq 0.06 \%$ ) (17).

These observations on SMCs in vitro raise the possibility that simply culturing SMCs causes the cells to undergo an irreversible switch to a replicative state. We have been interested in using SMCs as a vector for introducing genes of therapeutic importance in vivo, and it has become apparent that we need to know how cultured SMCs infected with replication-defective retrovirus and selected for their ability to grow in the presence of a neomycin analogue (G418) behave when seeded back into injured arteries (18). On the one hand, the seeded cells might behave as the endogenous SMCs and resume quiescence after a period of proliferation; on the other hand, they might preserve their in vitro behavior and continue to proliferate. Additionally, the presence of the provirus may alter the growth characteristics of the SMCs independent of the effects of in vitro culture. We have previously shown that rat SMCs containing the gene for human adenosine deaminase (hADA) stably express hADA activity for a minimum of 6 mo after being seeded back into injured rat carotid artery (18).

We demonstrate in this study that these retrovirus-infected SMCs proliferate for a limited time in the intima and stop dividing once the endothelium is restored on the luminal surface even though they continue to express the introduced human genes over the long term. These findings support the conclusion that the "cell culture phenotype" is reversible once the SMCs are replaced in an appropriate in vivo environment and that there are no adverse effects due to the presence of the retrovirus in the host genome. 


\section{Methods}

Retroviral vectors. The construction of the retroviral vectors encoding hADA and neomycin phosphotransferase (Neo) (LASN) or Neo alone (LXSN) has been described (18-20). The vectors are named based on the order of the genetic elements: $L$, long terminal repeat promoter; $S$, SV40 promoter; N, neo; A, ADA; and X, a cloning site for cDNA insertion. In LASN the hADA gene is transcribed from the viral long terminal repeat, and the neo gene is transcribed from an internal SV40 promoter. Clonal amphotropic vector-producing cell lines were generated using PA317 cells as previously described (19-21).

The plasmid form of the retroviral vector DAP that encodes alkaline phosphatase and Neo was kindly provided by S. C. Fields-Berry (22). We constructed another vector that encodes alkaline phosphatase and Neo by removing the alkaline phosphatase cDNA from DAP by using SalI and inserting this fragment into the XhoI site of pLXSN (20) to make pLAPSN. Both vectors were transfected into PE501 ecotropic retrovirus packaging cells, and transiently produced virus was used to infect PA317 amphotropic packaging cells as described (20). The titer of virus produced by PA317 cells containing LAPSN was $\sim 10$-fold higher than that of PA317 cells containing DAP, presumably due to the extended retroviral packaging signal present in pLAPSN that is not present in $\operatorname{DAP}(20,23) .1$ of 10 PA317 clones screened that produced the highest titer virus $\left(8 \times 10^{6} \mathrm{G} 418\right.$-resistant $\mathrm{CFU} / \mathrm{ml}$ ), and that contained an unrearranged LAPSN vector by Southern analysis and was helper virus free, was used for these studies.

Cell culture. Rat SMC cultures were prepared by enzymatic digestion of aortas from male Fischer 344 rats (Simonsen Laboratories, Gilroy, CA) with collagenase type I ( $167.5 \mathrm{U} / \mathrm{ml}$; Worthington Biochem. Corp., Freehold, NJ), elastase type III ( $15 \mathrm{U} / \mathrm{ml}$; Sigma Chemical Co., St. Louis, MO), soybean trypsin inhibitor $(364 \mu \mathrm{g} / \mathrm{ml}$; Worthington Biochem. Corp.), and bovine serum albumin $(2 \mathrm{mg} / \mathrm{ml}$; Sigma Chemical Co.) as described (18). The cells were characterized by immunocytochemistry. The cells stained positive with an antibody against SMC alpha actin (Boehringer Mannheim Biochemicals, Indianapolis, IN) while staining negative with an antibody against the endothelial cell-specific marker von Willebrand factor (Dako Corp., Carpinteria, $\mathrm{CA}$ ). The cells did not bind the EDI monoclonal antibody that recognizes rat myeloid cells or the MRC OX-22 anti-rat leukocyte common antigen antibody (Serotec, Indianapolis, IN).

SMC transduction and transplantation. Early passage (P4) SMCs were exposed to 16-h virus harvests from PA317/LXSN cl, PA317/ LASN cl, and PA317/LAPSN cl amphotropic vector-producing cell lines for a period of $24 \mathrm{~h}$ in the presence of Polybrene $(4 \mu \mathrm{g} / \mathrm{ml}$; Sigma Chemical Co.) (18). Infected cells were selected in $0.5 \mathrm{mg} / \mathrm{ml}$ active G418 (Gibco Laboratories, Grand Island, NY). In some experiments, the SMCs were stained in suspension with the fluorescent probe DiI ( $1,1^{\prime}$-dioctadecyl-3,3,3',3'-tetramethylindocarbocyanine perchlorate; stock solution, $5 \mathrm{mg} / \mathrm{ml}$, in DMSO; diluted 1:100 in culture medium containing the cells; Molecular Probes, Inc., Eugene, OR) for $30 \mathrm{~min}$ and then washed with culture medium just before seeding into the carotid arteries. Dil is an inert, nontoxic hydrophobic probe that exhibits rhodamine fluorescence. It labels the plasma membrane and is not transferred between membranes (24-28).

Male Fischer 344 rats ( $>300 \mathrm{~g}$ ) were anesthetized with pentobarbital, the left carotid artery was surgically exposed, and the distal half of the artery was temporarily isolated with ligatures and denuded of endothelium by the passage of a $2 \mathrm{~F}$ balloon catheter ( $\mathrm{V}$. Mueller, McGaw Park, IL) introduced through an arteriotomy in the external branch (17). Approximately $10^{6}$ transduced SMCs in $50 \mu \mathrm{l}$ culture medium were infused over $15 \mathrm{~min}$ into the isolated carotid segment by means of a cannula in the external carotid after a brief irrigation with DME/F12 (1:1 mixture) culture medium. The external carotid was ligated after removal of the catheter, blood flow restored, and the wound closed. Control animals were subjected to carotid balloon injury without cell seeding.

Morphology, morphometry, and measurement of SMC proliferation. After various time intervals, the animals were anesthetized and both carotid arteries together with the aortic arch were removed, either in a fresh state for ADA activity assay ( 1 and $12 \mathrm{mo}$ ) or after perfusion fixation for alkaline phosphatase staining and morphology. The vessels were fixed by perfusion of $10 \%$ neutral buffered formaldehyde at 100 $\mathrm{mmHg}$ at $2 \mathrm{~d}$ or $1,2,4,12$, or $24 \mathrm{wk}$ after balloon injury for $6 \mathrm{~min}$. The vessels were excised, fixed further by immersion in formaldehyde overnight, washed in phosphate-buffered saline, and embedded in paraffin for histologic cross sectioning. The vascular compartmental areas were measured on a histologic cross section at each of two sites per carotid. The rats received injections of $\left[{ }^{3} \mathrm{H}\right]$ thymidine $(0.5 \mathrm{mCi} / \mathrm{kg}$ i.p.; 6.7 $\mathrm{Ci} / \mathrm{mmol}$; New England Nuclear, Boston, MA) at 17,9, and $1 \mathrm{~h}$ before death. Autoradiograms were prepared from histologic cross section and the fraction of labeled nuclei was measured (thymidine labeling index) (17).

Four specimens at 1 mo were fixed in $2 \%$ paraformaldehyde/1\% glutaraldehyde in phosphate-buffered saline, $\mathrm{pH} 7.4$, washed in buffer, dehydrated, and embedded in Epon and thin sectioned for transmission electron microscopy. Similarly, fixed specimens at $2,7,14$, and 28 d (27 rats) were opened longitudinally, pinned out on Teflon sheets, dehydrated, dried by the critical point method, and examined by scanning electron microscopy to define the morphology at the luminal surface of the seeded carotid arteries.

Arteries seeded with Dil-labeled SMCs were retrieved in a fresh state at $2,7,14$, and $28 \mathrm{~d}$ (20 rats), frozen, and cross sectioned. The sections were examined under fluorescence using a rhodamine filter. Four arteries were retrieved fresh between 4 and $6 \mathrm{wk}$ and enzymatically digested with elastase and collagenase as described earlier. Cytological preparations on slides were made and stained with antibody against smooth muscle alpha actin using a fluorescein-tagged secondary antibody. The fraction of seeded (rhodamine-positive) and endogenous (rhodamine-negative) SMCs staining with the alpha actin antibody was determined.

Measurement of $h A D A$ and human placental alkaline phosphatase. ADA assays using starch gel electrophoresis were performed as previously described on five vessels seeded with SMCs containing hADA at 1 and 12 mo (18). Vector-encoded alkaline phosphatase was localized histochemically as described by Fields-Berry et al. (22). Whole carotid arteries previously perfusion fixed with neutral buffered formalin were washed in three changes of phosphate-buffered saline and incubated at $65^{\circ} \mathrm{C}$ for $30 \mathrm{~min}$ to eliminate endogenous activity since human placental alkaline phosphatase is 100 -fold more resistant to heat treatment than is rodent alkaline phosphatase. They were then incubated in a nitroblue tetrazolium-buffered solution for $16-24 \mathrm{~h}$ at room temperature in the dark. Stained arteries were embedded in paraffin and cross sectioned $(2,14$, and $28 \mathrm{~d}$, and 8 and $12 \mathrm{mo} ; 14$ rats $)$.

\section{Results}

Morphology of denuded rat carotid artery with and without seeded SMCs. The morphological observations in balloon-injured carotid arteries of Fischer 344 rats were very similar to those previously made by us in denuded carotid arteries of Sprague Dawley rats $(17,29)$. By scanning electron microscopy, the distal segment of the left carotid artery 24 and $48 \mathrm{~h}$ after balloon injury alone was devoid of endothelium, and the surface was covered with a monolayer of platelets without fibrin (Fig. $1 A$ ) (17). With time this layer of platelets was replaced by endothelial cells growing in from the ends of the zone of injury. By $4 \mathrm{wk}$ the endothelial layer was fully reestablished. The intima became progressively thicker on account of SMC and matrix accumulation. The intima reached a maximum by $4 \mathrm{wk}$, and intimal area was unchanged at $24 \mathrm{wk}$ (Fig. 2).

A number of differences were obvious in the vessels seeded with SMCs. By scanning microscopy, the luminal surface at 24 and $48 \mathrm{~h}$ was covered with clumps of platelets and fibrin (Fig. 1 $B$ ), and individual cells without adherent platelets were appar- 

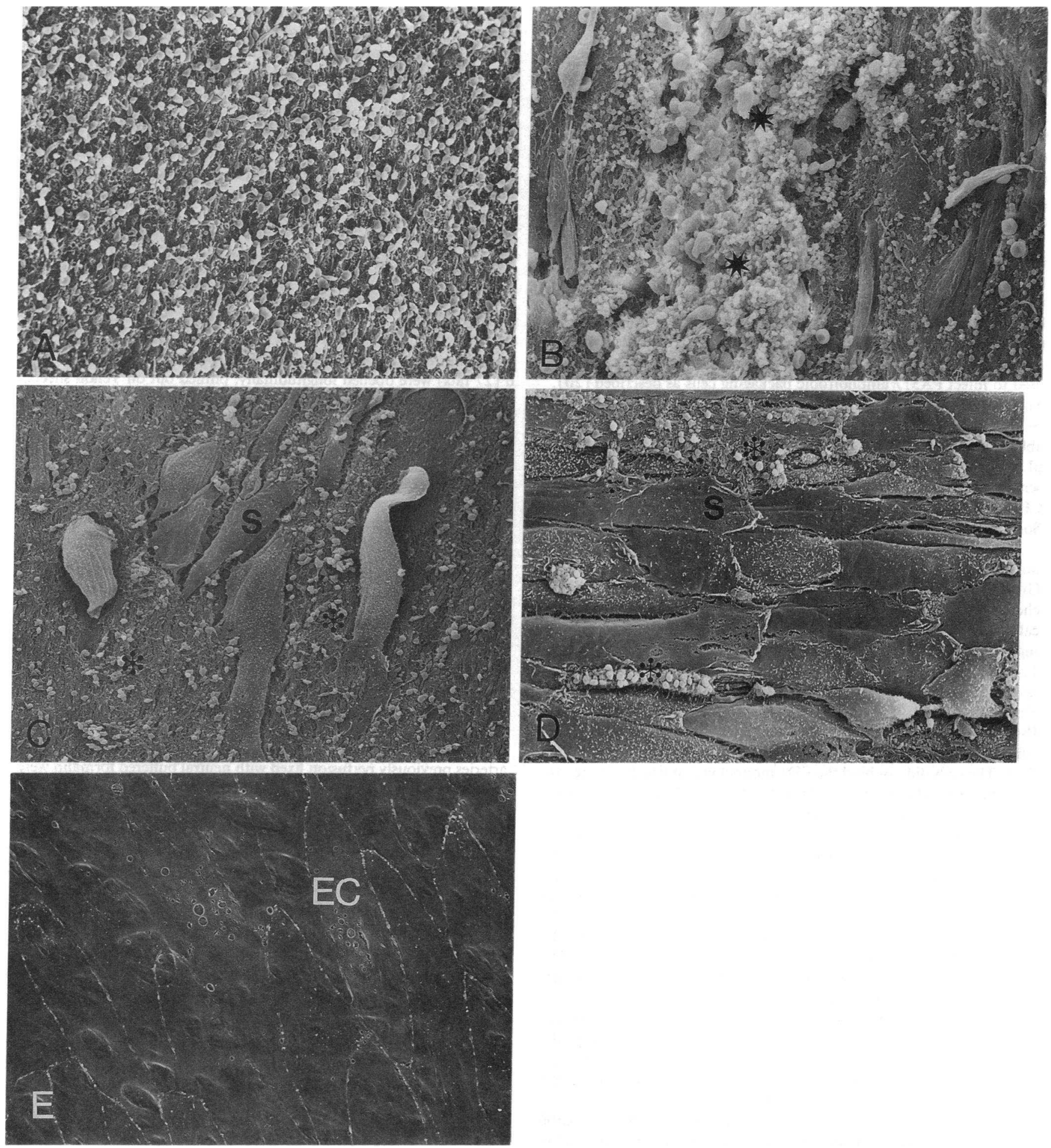

Figure 1. Scanning electron micrographs of the luminal surface of denuded carotid arteries without seeded SMCs at $2 \mathrm{~d}(A)$ or with seeded SMCs at $2 \mathrm{~d}(B$ and $C), 1 \mathrm{wk}(D)$, and $2 \mathrm{wk}(E)$. Note SMCs $(S)$ interspersed with aggregates of platelets $\left(^{*}\right)$. The unseeded and seeded vessels are largely covered by endothelium $(E C)$ by $2 \mathrm{wk}(\times 1,200)$.

ent at the surface (Fig. $1 C$ ). At $1 \mathrm{wk}$, the surface was populated with cells exhibiting the features of luminal SMCs (Fig. 1 D) (30). At $2 \mathrm{wk}$, the surface was largely covered by endothelial ingrowth from the ends of the seeded segment, and all vessels examined between 4 and 24 wk were covered with endothe- lium (Fig. $1 E$ ). The observations made by scanning microscopy were confirmed in histologic cross sections. In addition, the seeded SMCs tended to be distributed asymmetrically about the circumference of the vessels (Fig. 3, $A, B, E$, and $F$ ). By $1 \mathrm{wk}$, a thick, cellular intima had formed that did not 


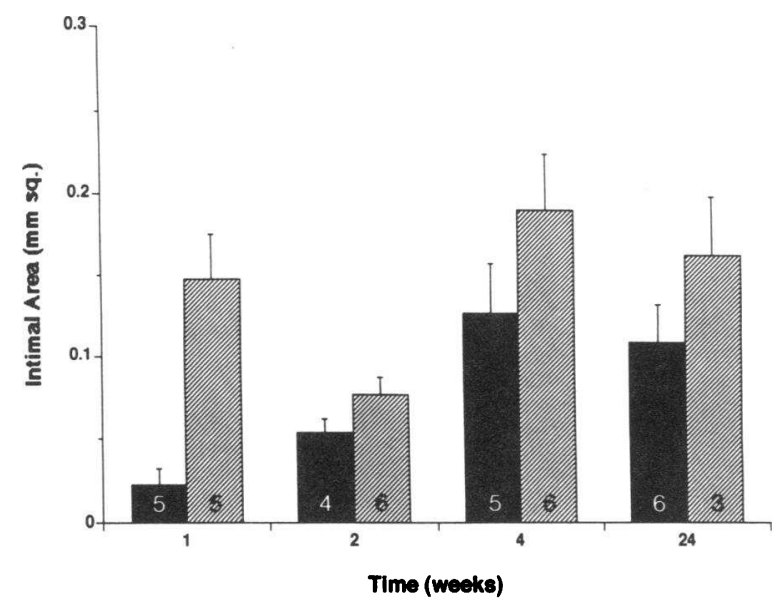

Figure 2. Graph of cross sectional intimal area (mean $\left.\left[\mathrm{mm}^{2}\right] \pm \mathrm{SE}\right)$ in balloon-injured rat carotid arteries with (cross-hatched bars) or without (solid bars) seeded SMCs at various times after surgery. Only the values at 1 wk are significantly different $(P<0.05$, Mann-Whitney $\mathrm{U}$ test). The number of animals studied per group is recorded in each bar.

change significantly at later times (Fig. 2). At $1 \mathrm{mo}$, the histologic appearance of balloon-injured carotid arteries with or without seeded cells was the same (Fig. 4, $A$ and $B$ ).

Time course of proliferation. Proliferation of SMCs was documented by pulse labeling with $\left[{ }^{3} \mathrm{H}\right]$ thymidine. In injured, unseeded arteries, thymidine labeling in the media was markedly increased during the first week and then declined (labeling index: $1 \mathrm{wk}, 21 \pm 8 \% ; 2 \mathrm{wk}, 0.6 \pm 0.2 \%)$. In the intima, labeling was maximal at $1 \mathrm{wk}$ and declined thereafter to low levels at $4 \mathrm{wk}$ (Fig. 5). At later times, SMC proliferation was $<0.1 \%$. These observations confirmed previous findings that SMC proliferation is at a maximum early after injury and spontaneously declines after $2 \mathrm{wk}$, particularly in regions covered by regenerating endothelium (17).

In vessels seeded with SMCs, thymidine labeling in the intima was the same as in unseeded vessels at all times, except at $1 \mathrm{wk}$ (Fig. 5). The labeling index in the media was maximal at $1 \mathrm{wk}$ and then declined ( $1 \mathrm{wk}, 21 \pm 2 \% ; 2 \mathrm{wk}, 0.5 \pm 0.2 \%$ ). At late times, very few labeled SMCs could be detected $(<0.1 \%)$.

Location and morphologic features of seeded SMCs. The location of SMC expressing retrovirally introduced genes was documented both by staining for human alkaline phosphatase and by chemically labeling the seeded cells with the lipophilic dye Dil. A polyclonal antibody to hADA purified by affinity chromatography using an hADA peptide bound to Sepharose and documented on Western blotting to identify human ADA but not rat ADA did not prove to be a useful immunohistochemical reagent. SMCs transduced with replication-defective retrovirus containing alkaline phosphatase in culture expressed a variable amount of alkaline phophatase. When seeded into injured rat carotid arteries, these cells were noted to localize primarily to the intima although occasional cells expressing alkaline phosphatase were observed in the media (Fig. 3, $A-C$ ). Arteries seeded with SMCs containing LXSN (Fig. $3 D$ ) or arteries that were only injured exhibited no intimal or medial stain. Examination of frozen cross sections of arteries seeded with SMC labeled with DiI confirmed the alkaline phosphatase histochemical studies and demonstrated fluorescent cells pri- marily in the intima (Fig. 3, E-H). At 2 wk portions of the intima were occupied by cells not labeled by alkaline phosphatase or Dil (Fig. 3, $B, F$, and $H$ ).

The intimal cells in seeded arteries stained with the antibody to rat SMC alpha actin. At late times, morphologic features of quiescent SMCs were demonstrated by transmission electron microscopy, including abundant myofilaments, an enveloping external lamina, and little rough endoplasmic reticulum (data not shown) $(1,2,30)$. In dispersions of cells enzymatically derived from arteries 4-6 wk after seeding with rhodamine-labeled SMCs, both seeded cells (rhodamine positive) and endogenous cells ( rhodamine negative) stained with antibody to smooth muscle alpha actin ( $>95 \%$ of cells). The luminal surface of the intima was covered after 1 mo with cells exhibiting the morphologic features of endothelium (30).

Long-term expression of hADA and alkaline phosphatase. Although the seeded intimal cells resumed quiescence and exhibited the morphologic features of resting quiescent SMC, those containing LASN continued to express significant amounts of hADA at $12 \mathrm{mo}$ (Fig. 6). hADA activity was found in all five vessels examined at $12 \mathrm{mo}$, and the range of activity was approximately the same as was found at $1 \mathrm{mo}$ (5-50\% of total activity) although insufficient material was available for more than visual estimation. Human alkaline phosphatase could be detected histochemically at $12 \mathrm{mo}$ in the intimas of all three arteries seeded with SMCs containing LAPSN (Fig. 7).

\section{Discussion}

The purpose of this study was to define the proliferative response of rat carotid artery seeded with cultured SMCs previously infected with replication-defective retrovirus containing hADA or alkaline phosphatase. We demonstrated that these cells form an intima and proliferate to nearly the same extent as endogenous SMCs. It is of note that the seeded cells resumed a quiescent state after a period of time even though they had been selected in vitro for their ability to proliferate. At late times ( 1 and $12 \mathrm{mo}$ ) they continued to express the retrovirally introduced genes with no perturbation of intimal growth.

Intimal thickening after arterial injury: the usual response. In the balloon-injured rat carotid artery, medial SMCs start synthesizing DNA at $24 \mathrm{~h}$ after injury and begin to migrate through the internal elastic lamina into the intima at $\sim 4 \mathrm{~d}(8$, 17). The intimal cells then undergo several rounds of division before resuming quiescence. Proliferation ceases spontaneously even if endothelium is absent. Although migration and proliferation of SMCs account for much of the intimal thickening, the final structure is, in fact, largely composed of matrix synthesized by the vascular wall cells (29).

The factors controlling intimal thickening are just now being defined. The first wave of proliferation is largely regulated by the extent of medial damage and the action of basic fibroblast growth factor released from the traumatized vascular wall cells (31-33). Migration into the intima is controlled by factors from platelets (34). PDGF itself appears to be a SMC migratory factor in this model $(35,36)$. The determinants of intimal structure have yet to be defined. Early reendothelialization and increased blood flow are associated with diminished intimal SMC growth $(31,37)$. Whether these events have more to do with decreased availability of growth factor or increased accumulation of inhibitor is not known. 

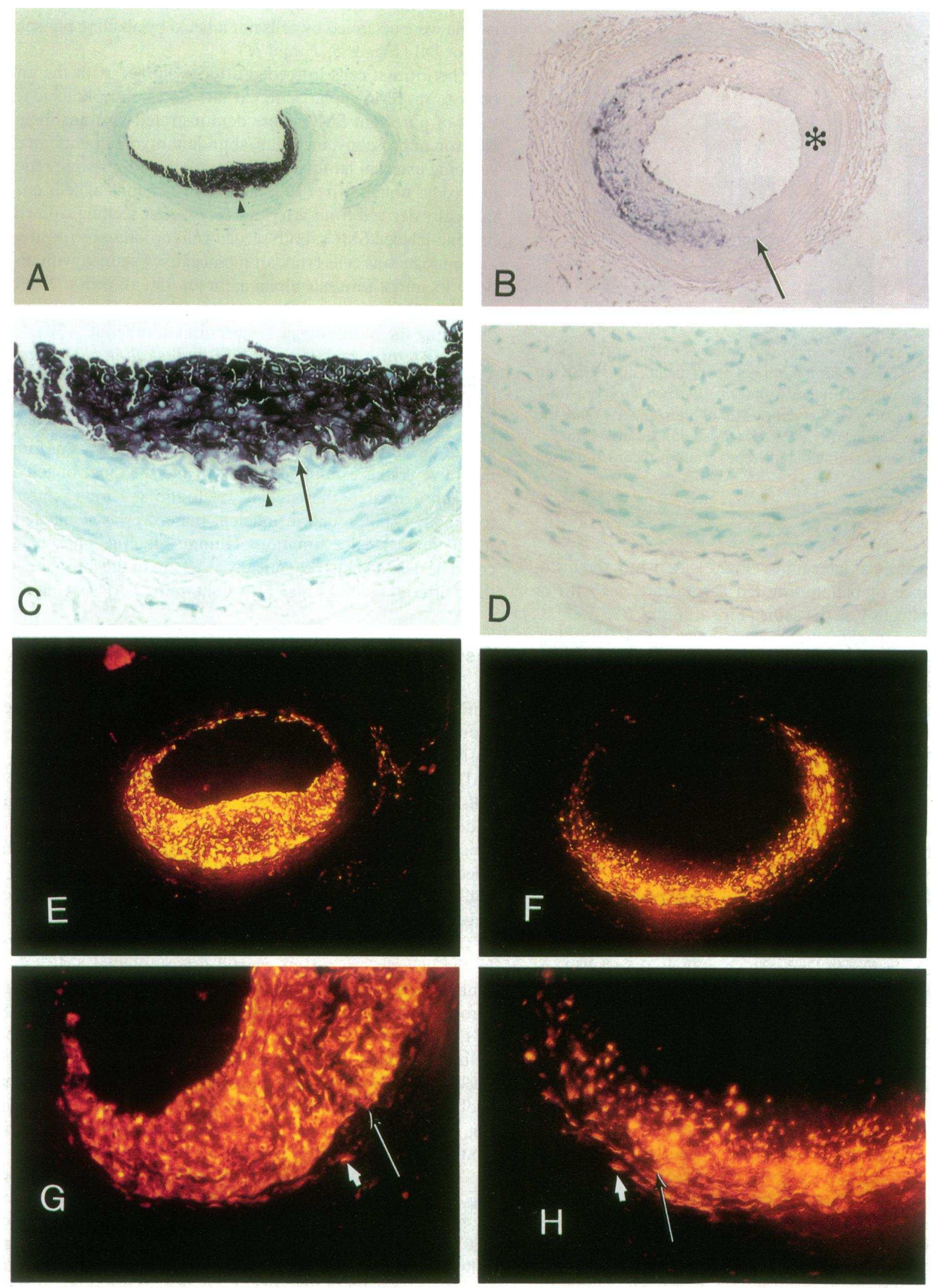

Figure 3. Histologic cross sections of injured carotid arteries seeded with SMCs expressing alkaline phosphatase $(A-C)$ or Dil $(E-H)$ at $2 \mathrm{~d}(A, C$, $E$, and $G)$ and $14 \mathrm{~d}(B, F$, and $H)$. Alkaline phosphatase reaction product stains black, and the Dil fluoresces yellow-orange. Note asymmetric distribution of the labeled cells and the presence of unlabeled cells $\left({ }^{*}\right)$ in the intima $(B)$. Note also the presence of labeled SMCs in the media (arrowhead) $(C, G$, and $H)$. 2-wk vessel treated by balloon injury alone $(D)$ does not stain for alkaline phosphatase. (Arrow) Internal elastic lamina $(A, B, E$, and $F: \times 170 ; C, D, G$, and $H: \times 780)$. 

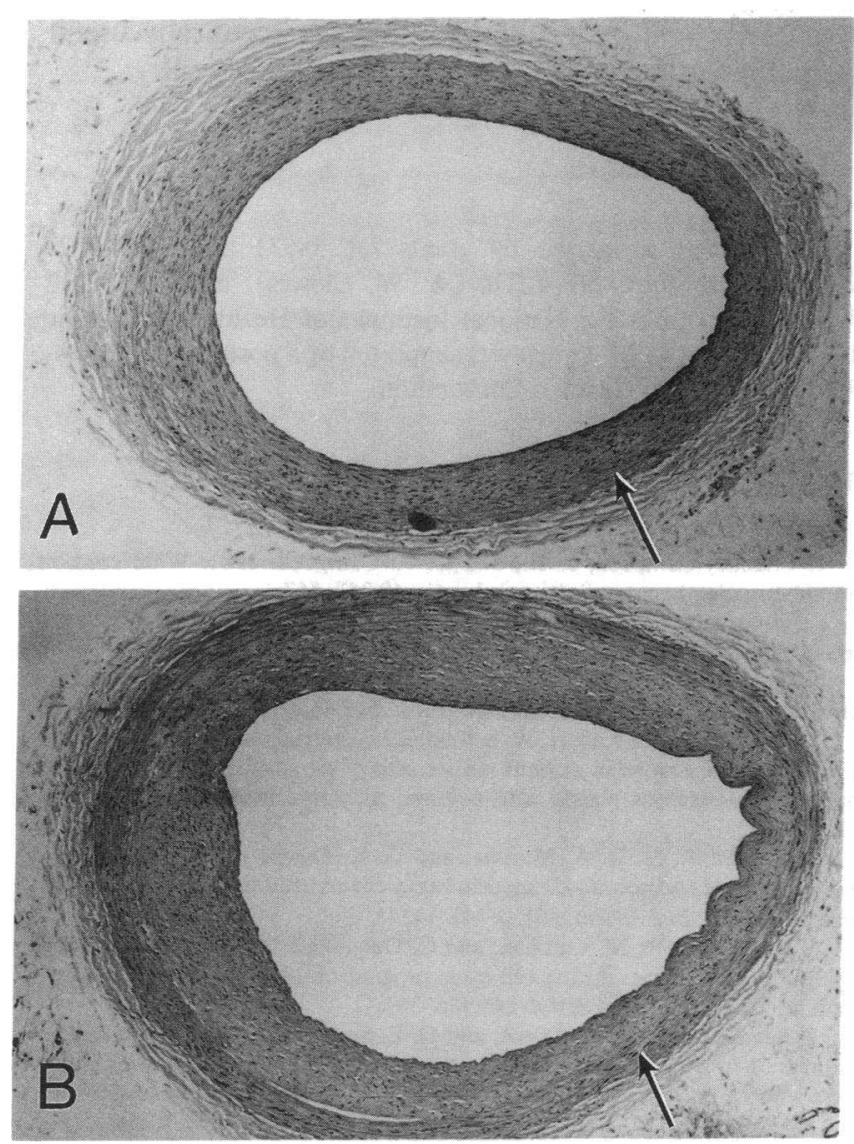

Figure 4. Histologic cross sections of arteries without $(A)$ and with $(B)$ seeded SMCs containing hADA at $1 \mathrm{mo}(\times 240)$.

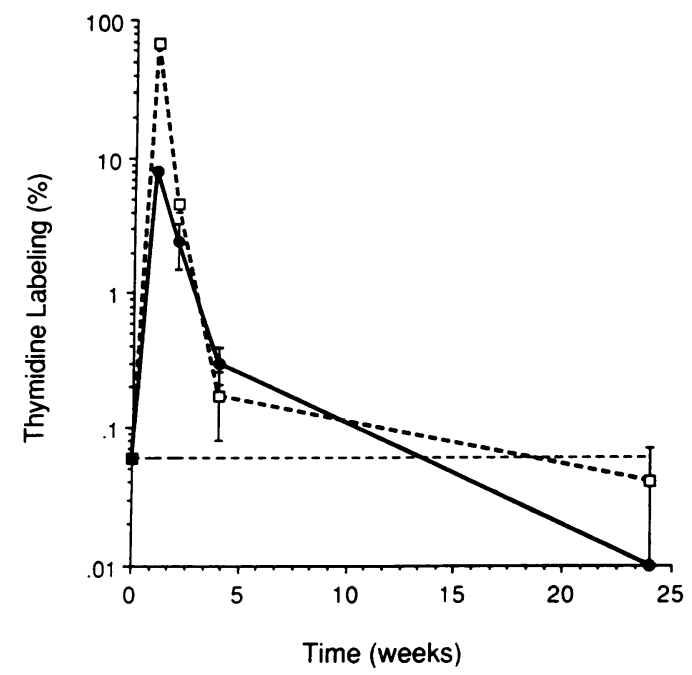

Figure 5. Graph depicts time course of intimal SMC proliferation (mean [percent thymidine labeling] $\pm S E$ ) between 1 and 24 wk in balloon-injured carotid arteries with (filled circles) or without (open squares) cell seeding. (Dashed line) Thymidine labeling index in uninjured carotid arteries. Only the values at 1 wk are significantly different (unseeded: $68 \pm 6$ vs. $8 \pm 1 \% ; P<0.05$, Mann-Whitney $U$ test). $n=5$ animals per group except at $24 \mathrm{wk}$ ( $n=3$ animals/group).

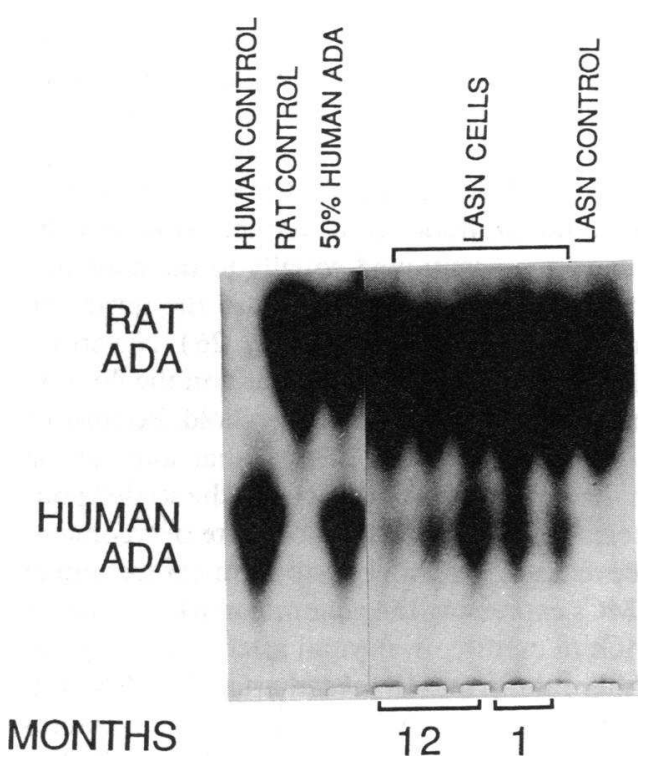

Figure 6. Starch gel analysis of ADA in rat carotid arteries seeded with SMCs containing LASN (LASN cells) at 1 and 12 mo. Extracts from two-seeded vessels at 1 mo and three-seeded vessels at 12 mo are shown. Extracts of LXSN-containing SMCs ( LASN CONTROL), human T cells ( HUMAN CONTROL), and rat thymocytes ( $R A T$ CONTROL), and a 1:1 mixture of human $T$ cell and rat thymocyte extracts ( $50 \%$ human ADA), are included to demonstrate positions of rat and human ADA bands. Equal ADA activity was loaded in each well.

Intimal thickening in arteries seeded with SMCs expressing hADA or alkaline phosphatase. We observed many similarities between the seeded and unseeded arteries and some notable, and expected, differences. An intimal thickening of cells and thrombus was formed immediately in the seeded, injured arteries while in the arteries subjected to injury alone intimal thickening was not really apparent until $1 \mathrm{wk}$ and contained only cells and surrounding matrix. Thrombosis is not normally a prominent feature of the response to injury in the rat carotid artery. The seeded cells remained in the intima and occasionally appeared to migrate backwards into the media. They also were distributed asymmetrically around the internal elastic

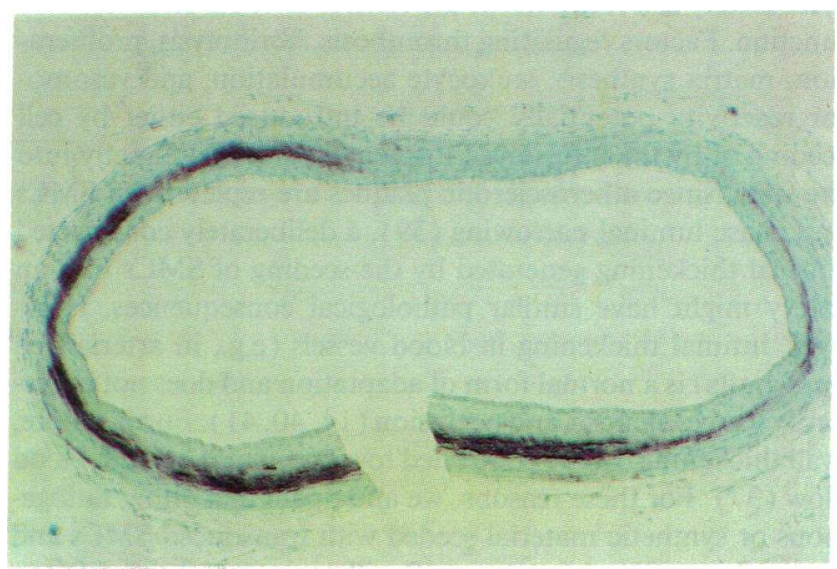

Figure 7. Histologic cross section of injured artery seeded with SMCs expressing alkaline phosphatase (black stain) at $12 \mathrm{mo}(\times 170)$. 
lamina probably because of gravitational pooling at the time of seeding. Many of the cells in the intima at later times were unlabeled and therefore were probably derived from endogenous medial SMCs.

We were able to label the seeded SMCs with the fluorochrome DiI. This nontoxic fluorescent marker remains with the cell membrane and is partitioned equally to the daughter cells during mitosis. It does not leach out into the serum or move between labeled and unlabeled cells $(24,26)$. Nevertheless, as the cells undergo several rounds of division the fluorescent signal diminishes to an undetectable threshold. Because of this attenuation of fluorescence, it is possible that some of the unlabeled cells in the intima were derived from the seeded population. The deficiencies of the DiI method were overcome to some extent by developing a reliable histochemical technique for identifying SMCs expressing the genomic marker, alkaline phosphatase. SMCs in culture, in normal artery, in artery undergoing repair after injury, and in seeded artery (LXSN-containing cells) do not have detectable heat-stable human placental alkaline phosphatase. The results of the DiI and alkaline phosphatase studies were generally in agreement and support the conclusion that the intima of seeded arteries at late times contained SMCs derived from both culture and endogenous sources.

The intimal labeling index in seeded arteries was significantly less than in unseeded arteries at $1 \mathrm{wk}$ and was the same at later times. In both conditions, SMC proliferation was at background levels by $1 \mathrm{mo}$. These observations support the conclusion that the seeded cells were not selected and programmed to proliferate indefinitely. By morphological criteria, these seeded intimal cells resembled intimal SMCs in arteries subjected to injury alone. Despite the manipulations in vitro, including transition to the culture environment, viral transduction, and G418 selection, these cells showed no obvious phenotypic difference other than the expression of the virally introduced genes. This lack of change is reassuring to us, as it would not be desirable to introduce into humans a cell type prone to neoplasia.

SMCs as a target for gene therapy. Vascular SMCs express retrovirally introduced genes over the long term ( $12 \mathrm{mo}$ ) without any apparent adverse effects. Other cell types, such as fibroblasts, do not exhibit long-term gene expression posttransplantation (38). In addition to SMCs serving as a potential vector for gene replacement therapy, they might also be used to express locally active agents for the control of vessel structure and function. Factors regulating thrombosis, fibrinolysis, proliferation, matrix synthesis, leukocyte accumulation, and vasomotor reactivity potentially could be introduced either by cell seeding or by the infusion of the genetic material directly into the wall. Since atherosclerotic plaques are replete with SMCs and cause luminal narrowing (39), a deliberately constructed intimal thickening generated by the seeding of SMCs into an artery might have similar pathological consequences. However, intimal thickening in blood vessels (e.g., in arterialized vein grafts) is a normal form of adaptation and does not necessarily lead to stenosis and occlusion (14, 40, 41). Furthermore, wall thickening can be controlled to some extent by high blood flow (37). For these reasons, we anticipate that either autogenous or synthetic material seeded with transduced SMCs and inserted as an arteriovenous graft will prove useful and safe as a means for introducing genes of therapeutic importance. In addition, we are hopeful that alternative vectors currently under investigation will permit efficient and therapeutically useful levels of direct gene transfer in vivo in the vessel wall.

\section{Acknowledgments}

This work was supported by grants DK-38531 and DK-43727 (W. R. A. Osborne), HL-42270 (A. W. Clowes), and HL-41212 (A. D. Miller) from the National Institutes of Health (U.S. Public Health Service). C. M. Lynch was supported by a postdoctoral fellowship from Targeted Genetics Corporation.

\section{References}

1. Chamley-Campbell, J. H., and G. R. Campbell. 1981. What controls smooth muscle phenotype? Atherosclerosis. 40:347-357.

2. Schwartz, S. M., G. R. Campbell, and J. H. Campbell. 1986. Replication of smooth muscle cells in vascular disease. Circ. Res. 58:427-444.

3. Kocher, O., O. Skalli, W. S. Bloom, and G. Gabbiani. 1984. Cytoskeleton of rat aortic smooth muscle cells. Lab. Invest. 50:645-652.

4. Gabbiani, G., O. Kocher, W. S. Bloom, J. Vandekerckhove, and K. Weber. 1984. Actin expression in smooth muscle cells of rat aortic intimal thickening human atheromatous plaque, and cultured rat aortic media. J. Clin. Invest. 73:148-152.

5. Rovner, A. S., R. A. Murphy, and G. K. Owens. 1986. Expression of smooth muscle and nonmuscle myosin heavy chains in cultured vascular smooth muscle cells. J. Biol. Chem. 261:14740-14745.

6. Gadeau, A.-P., M. Campan, and C. Desgranges. 1991. Induction of cell cycle-dependent genes during cell cycle progression of arterial smooth muscle cells in culture. J. Cell. Physiol. 146:356-361.

7. Kindy, M. S., K. E. Brown, and G. E. Sonenshein. 1991. Regulation of expression of the growth-state-related genes $2 \mathrm{~F} 1$ and $2 \mathrm{~A} 9$ during entry of quiescent smooth muscle cells into the cell cycle. J. Cell. Biochem. 46:345-350.

8. Majesky, M. W., S. M. Schwartz, M. M. Clowes, and A. W. Clowes. 1987. Heparin regulates smooth muscle $S$ phase entry in the injured rat carotid artery. Circ. Res. 61:296-300.

9. Majesky, M., E. P. Benditt, and S. M. Schwartz. 1988. Expression and developmental control of platelet-derived growth factor A-chain and B-chain/sis genes in rat aortic smooth muscle cells. Proc. Natl. Acad. Sci. USA. 85:15241528.

10. Majesky, M. W., M. A. Reidy, D. F. Bowen-Pope, C. E. Hart, J. N. Wilcox, and S. M. Schwartz. 1990. PDGF ligand and receptor gene expression during repair of arterial injury. J. Cell Biol. 111:2149-2158.

11. Majesky, M. W., C. M. Giachelli, M. A. Reidy, and S. M. Schwartz. 1992. Rat carotid neointimal smooth muscle cells reexpress a developmentally regulated mRNA phenotype during repair of arterial injury. Circ. Res. 71:759-768.

12. Reilly, C. F., M. S. Kindy, K. E. Brown, R. D. Rosenberg, and G. E. Sonenshein. 1989. Heparin prevents vascular smooth muscle cell progression through the G1 phase of the cell cycle. J. Biol. Chem. 264:6990-6995.

13. Brown, K. E., M. S. Kindy, and G. E. Sonenshein. 1992. Expression of the c-myb proto-oncogene in bovine vascular smooth muscle cells. J. Biol. Chem. 267:4625-4630.

14. Schwartz, S. M., R. L. Heimark, and M. W. Majesky. 1990. Developmental mechanisms underlying pathology of arteries. Physiol. Rev. 70:1177-1210.

15. Campbell, J. H., O. Kocher, O. Skalli, G. Gabbiani, and G. R. Campbell. 1989. Cytodifferentiation and expression of alpha-smooth muscle actin mRNA and protein during primary culture of aortic smooth muscle cells. Correlation with cell density and proliferative state. Arteriosclerosis. 9:633-643.

16. Kocher, O., and G. Gabbiani. 1986. Expression of actin mRNA in rat aortic smooth muscle cells during development, experimental intimal thickening. and culture. Differentiation. 32:245-251.

17. Clowes, A. W., M. A. Reidy, and M. M. Clowes. 1983. Kinetics of cellular proliferation after arterial injury. I. Smooth muscle growth in the absence of endothelium. Lab. Invest. 49:327-333.

18. Lynch, C. M., M. M. Clowes, W. R. A. Osborne, A. W. Clowes, and A. D. Miller. 1992. Long-term expression of human adenosine deaminase in vascular smooth muscle cells of rats: a model for gene therapy. Proc. Natl. Acad. Sci. USA. 89:1138-1142.

19. Hock, R. A., A. D. Miller, and W. R. A. Osborne. 1989. Expression of human adenosine deaminase from various strong promoters after gene transfer into human hematopoietic cell lines. Blood. 74:876-881.

20. Miller, A. D., and G. J. Rosman. 1989. Improved retroviral vectors for gene transfer and expression. BioTechniques. 7:980-990.

21. Miller, A. D., and C. Buttimore. 1986. Redesign of retrovirus packaging cell lines to avoid recombination to helper virus production. Mol. Cell. Biol. 6:2895-2902. 
22. Fields-Berry, S. C., A. L. Halliday, and C. L. Cepko. 1992. A recombinant retrovirus encoding alkaline phosphatase confirms clonal boundary assignment in lineage analysis of murine retina. Proc. Natl. Acad. Sci. USA. 89:693-697.

23. Bender, M. A., T. D. Palmer, R. E. Gelinas, and A. D. Miller. 1987. Evidence that the packaging signal of Moloney murine leukemia virus extends into the gag region. J. Virol. 61:1639-1646.

24. Honig, M. G., and R. I. Hume. 1986. Fluorescent carbocyanine dyes allow living neurons of identified origin to be studied in long-term cultures. J. Cell Biol. 103:171-187.

25. Serbedzija, G. N., M. Bronner-Fraser, and S. E. Fraser. 1989. A vital dye analysis of the timing and pathways of avian trunk neural crest cell migration. Development (Camb.). 106:809-816.

26. Serbedzija, G. N., S. E. Fraser, and M. Bronner-Fraser. 1990. Pathways of trunk neural crest cell migration in the mouse embryo as revealed by vital dye labelling. Development (Camb.). 108:605-612.

27. Pomeranz, H. D., T. P. Rothman, and M. D. Gershon. 1991. Colonization of the post-umbilical bowel by cells derived from the sacral neural crest: direct tracing of cell migration using an intercalating probe and a replication-deficient retrovirus. Development (Camb.). 111:647-655.

28. Bagnall, K. M. 1992. The migration and distribution of somite cells after labelling with the carbocyanine dye, Dil: the relationship of this distribution to segmentation in the vertebrate body. Anat. Embryol. 185:317-324.

29. Clowes, A. W., M. A. Reidy, and M. M. Clowes. 1983. Mechanisms of stenosis after arterial injury. Lab. Invest. 49:208-215.

30. Clowes, A. W., R. E. Collazzo, and M. J. Karnovsky. 1978. A morphologic and permeability study of luminal smooth muscle cells after arterial injury in the rat. Lab. Invest. 39:141-150.

31. Fingerle, J., Y. P. T. Au, A. W. Clowes, and M. A. Reidy. 1990. Intimal lesion formation in rat carotid arteries after endothelial denudation in absence of medial injury. Arteriosclerosis. 10:1082-1087.
32. Lindner, V., D. A. Lappi, A. Baird, R. A. Majack, and M. A. Reidy. 1991. Role of basic fibroblast growth factor in vascular lesion formation. Circ. Res 68:106-113.

33. Lindner, V., and M. A. Reidy. 1991. Proliferation of smooth muscle cells after vascular injury is inhibited by an antibody against basic fibroblast growth factor. Proc. Natl. Acad. Sci. USA. 88:3739-3743.

34. Fingerle, J., R. Johnson, A. W. Clowes, M. W. Majesky, and M. A. Reidy. 1989. Role of platelets in smooth muscle cell proliferation and migration after vascular injury in rat carotid artery. Proc. Natl. Acad. Sci. USA. 86:8412-8416.

35. Ferns, G. A. A., E. W. Raines, K. H. Sprugel, A. S. Motani, M. A. Reidy, and R. Ross. 1991. Inhibition of neointimal smooth muscle accumulation afte angioplasty by an antibody to PDGF. Science (Wash. DC). 253:1129-1132.

36. Jawien, A., D. F. Bowen-Pope, V. Lindner, S. M. Schwartz, and A. W. Clowes. 1992. Platelet-derived growth factor promotes smooth muscle migration and intimal thickening in a rat model of balloon angioplasty. J. Clin. Invest. 89:507-511.

37. Kohler, T. R., and A. Jawien. 1992. Flow affects development of intimal hyperplasia after arterial injury in rats. Arterioscler. Thromb. 12:963-971.

38. Palmer, T. D., G. J. Rosman, W. R. A. Osborne, and A. D. Miller. 1991. Genetically modified skin fibroblasts persist long after transplantation but gradually inactivate introduced genes. Proc. Natl. Acad. Sci. USA. 88:1330-1334.

39. Reuterdahl, C., C. Sundberg, K. Rubin, K. Funa, and B. Gerdin. 1993 Tissue localization of $\beta$ receptors for platelet-derived growth factor and plateletderived growth factor B chain during wound repair in humans. J. Clin. Invest. 91:2065-2075.

40. Carrel, A., and C. C. Guthrie. 1906. Results of the biterminal transplantation of veins. Am. J Med. Sci. 132:415-422.

41. Zwolak, R. M., M. C. Adams, and A. W. Clowes. 1987. Kinetics of vein graft hyperplasia: association with tangential stress. J. Vasc. Surg. 5:126-136. 